San Jose State University SJSU ScholarWorks

Master's Theses

Master's Theses and Graduate Research

Fall 2010

\title{
String Quartet No. 1
}

Jeffrey Scott Perry

San Jose State University

Follow this and additional works at: https://scholarworks.sjsu.edu/etd_theses

\section{Recommended Citation}

Perry, Jeffrey Scott, "String Quartet No. 1" (2010). Master's Theses. 3889.

DOI: https://doi.org/10.31979/etd.aast-3ssq

https://scholarworks.sjsu.edu/etd_theses/3889

This Thesis is brought to you for free and open access by the Master's Theses and Graduate Research at SJSU ScholarWorks. It has been accepted for inclusion in Master's Theses by an authorized administrator of SJSU ScholarWorks. For more information, please contact scholarworks@sjsu.edu. 
STRING QUARTET NO. 1

\author{
A Thesis \\ Presented to \\ The Faculty of the School of Music and Dance \\ San José State University \\ In Partial Fulfillment \\ of the Requirements for the Degree \\ Master of Arts
}

by

Jeffrey Scott Perry

December 2010 
(C) 2010

Jeffrey Scott Perry

ALL RIGHTS RESERVED 
The Designated Thesis Committee Approves the Thesis Titled

STRING QUARTET NO. 1

by

Jeffrey Scott Perry

APPROVED FOR THE SCHOOL OF MUSIC AND DANCE

SAN JOSÉ STATE UNIVERSITY

December 2010

Dr. Brian Belet

Dr. Pablo Furman

Dr. Aaron Lington
School of Music and Dance

School of Music and Dance

School of Music and Dance 


\title{
ABSTRACT
}

\section{STRING QUARTET NO. 1}

\author{
by Jeffrey Scott Perry
}

This quartet is absolute music, which is music that is dependent only on its structure for comprehension and not associated with extra-musical ideas or emotions. It uses unconventional techniques, lacking traditional melodies and harmonies, that challenge both performers and listeners to interpret the music in non-traditional ways. Performers are given flexibility in their treatment of tempo and phrasing that yields a different version of the piece each time it is performed so that listeners remain attentive. The structure is a simple A-B-A' design. However, the structure is manipulated to be purposefully obscure until the last measures of the piece. This is accomplished by incorporating ideas of motivic development (fragmentation, augmentation, diminution, retrograde, and inversion) into the overall form. The first four motifs are the source of all subsequent material. Therefore, motivic development is vital to the construction of the piece and becomes a unifying factor between both melodic and formal identities. There is no intentional harmonic progression as the piece derives itself from four independent and unique motifs. This directs the listener to focus on the tension and release that occurs linearly and not vertically. Musical color, without the use of tertian harmony, relies on other music elements such as timbre, texture, tempo, dynamics, transposition, and the idiomatic use of bowed string instruments. 


\section{ACKNOWLEDGEMENTS}

Sincere thanks go to Dr. Brian Belet, who acted as an invaluable mentor not only to the creation of this thesis, but to the professional and personal growth required to sustain a career in the music industry. Dr. Furman has also played an integral part in shaping the identity of this work through patience and understanding, and by providing insight, opportunity, enthusiasm, and experience. Countless other faculty members at San José State University, too many of which to name, deserve much credit for their resources and guidance. 


\section{TABLE OF CONTENTS}

Introduction $\quad 1$

String Quartet No. 1 


\section{INTRODUCTION}

The design of String Quartet No. 1, by Jeffrey Scott Perry, is meant to challenge traditional formal structure to produce an aesthetic that is interesting to both listeners and performers. The music is absolute. There is no reference to emotions or ideas, and it is the opposite of programmatic music. The notes themselves and the way they are treated, along with phrase structure and overall form, are the focal points of the piece. Performers of the piece are challenged to interpret it in non-traditional ways that will yield a different version of the piece each time it is performed, therefore making each performance a premier performance for listeners. There is no focus on traditional harmony. Instead, the focus shifts to how the music creates tension and resolves it. This is accomplished through form, by strict motivic development of the motifs, and by generating different aesthetics in tone color through the use of timbre, texture, tempo, meter, dynamics, transposition, and the idiomatic use of bowed string instruments.

The form of the piece is A-B-A', otherwise known as Rounded Binary form. The choice to use a simple structure counters the non-traditional use of melody and harmony or the lack thereof. In other words, it keeps the intentional chaos from getting out of control. The section divisions, however, may not be immediately clear upon the first listen, or initial score examination. But they are clear and obvious once you recognize them. The listener can then, without interruption, be absorbed into a single, fluid piece from beginning to end. The sections are based upon the use of meter/no meter, motivic 
development, and/or varying tempos throughout the piece. Each section utilizes different methods of motivic development.

The first A-section ends at measure 7 after the first four motifs are introduced, repeated, augmented and diminished, and passed twice amongst the instruments. It incorporates the use of varying tempos occurring simultaneously between the instruments. There is no meter. As each motif is introduced, it receives a tempo range that, as the performer repeats, varies with each pass. Inevitably, as more motifs occur, the variation in tempo increases as the rhythm of the other performers pulls each performer away from his or her rhythm.

Motivic development occurs in measures 5 and 6 with the use of augmentation, diminution, transposition, and retrograde. There are four motifs that enter one after another. These motifs will hereafter be identified in the order in which they appear. The motif stated first in the viola part will be motif 1 , the second violin's motif will be motif 2 , the cello's motif will be motif 3 , and the first violin's motif will be motif 4 . In measure 5 , the second violin augments the rhythm of motif 1 by double note values. In the same measure the cello also augments the rhythm of motif 2 by double note values, and the first violin does the same with motif 3 . The viola, however, does nothing to motif 4. This is a transition device amidst the changing parts. The motif is passed to a new instrument, but the continuation of one motif helps the transition seem fluid and seamless. In measure 6 , the first violin transposes motif 2 up a perfect fifth. The second violin diminishes motif 3 by double note values, as well as transposing it up a perfect fourth. The viola transposes motif 1 by a perfect fifth and also plays it in retrograde. The 
cello transposes motif 4 up a perfect fourth, and utilizes retrograde inversion. The first violin and viola both transpose by a perfect fifth, and the second violin and cello transpose by a perfect fourth. Both of these intervals, when inverted, are the same. This function is a transition device to seamlessly connect the motivic changes as everything moves together in similar fashion.

Section B begins at measure 7 and ends at measure 86 . It begins with a single tempo and meter for all instruments. The section is a development of the four motifs, incorporating only elements found in those motifs. The cello begins alone with an augmented, transposed, and fragmented retrograde version of motif 1 , repeating five times making it an ostinato. This change in texture from the denseness of the end of section A resolves tension. Sustaining long tones over changing meters between 6/4,5/4, $4 / 4$, and $3 / 4$ obscures the sense of pulse so that the music flows without a sense of time, opposite of the individual motifs happening in section A. One might call this musical irony as the first section has no meter, but has a clear sense of pulse within each motif, but now has meter, but no sense of pulse. The restatement of motif 1 is a unifying factor that prepares for the ensuing development. And, it signifies that motif 1 is the primary motif to which the piece will come back to in the end.

The viola enters at measure 14 and the cello's ostinato phrase is in diminished form. It is delayed by three beats from the cello to create rising tension. After one statement of the phrase the viola begins similarly at measure 21 , but diminished by half of the note values. At that same point, the phrase is passed to the second violin, which, in turn, states it one time. The first violin enters at measure 20 with harmonic tones that 
serve to double, at a higher register, notes from the cello part. The role taken here is to add texture and color and not to add another layer in the tension. However, at measure 22 , the first violin, while still doubling notes from the cello, hints at motif 1 with a quiet pizzicato tone in sixteenth note rhythm.

At measure 28, all parts begin to fully develop using all the tools of motivic development, borrowing clips from all four of the original motifs. The tempo slows slightly, but the rhythm of the notes increases and all parts become busy, except for the cello that still holds an ostinato. Tension is rising and, traditionally, it would be described as a new period. But the overlapping cello ostinato serves to obscure the change. Carefully placed rests within each part shifts focus to the most active part. The piece is beginning to allude to the free-time of the beginning A-section. More active dynamic placements help the music swell and distinguish the colors of each phrase. The expression changes from Broad and Tranquil, to Animated help performers add character and color to the piece.

Finally, at measure 42, the ostinato of the cello disappears and the cello joins the ongoing development of the motifs. The expression changes to Lively, the meter changes to $4 / 4$ and the tempo becomes quicker. A new level of tension is mounting. One could think of the tension sequence as step-tension, similar to step-dynamics in Giovanni Gabrieli's time. In fact, the rehearsal markings in the piece are there to signify sections of stronger or weaker tension. Less rests are also used at measure 42 that no longer isolate phrases. The result obscures the sense of overall pulse. However, 4/4 meter controls what seems to be growing chaos, and an inevitable return of the A-section, by 
adding a sense of beat to the performer, whom has, since youth, been trained to demarcate beat distinctions across measure-lines, especially in the most common of all meters.

The meter changes to $8 / 8$ at measure 51 and creates a strong sense of pulse that relieves the tension of no sense of pulse from previous measures. Measure 50 is in 7/4 time that acts as a transition to the new meter and beat groupings. The meter at measure 51 is $8 / 8$ and not $4 / 4$ because of the underlying beat groupings of $3+2+2+3$. The expression marking is Lively and Agitated, and is a direct allusion of the return to section A. The tempo is very fast to ensure that tension builds quickly. The first violin and viola share a common rhythm that is built from an augmented fragment of motif 2. Similarly, the cello and second violin share a common rhythm derived from a fragment of motif 3 . This continues to measure 59, where a new rhythm is introduced to the first violin and viola. Their beat grouping now is $2+3+3+2$, an inverse from the previous grouping. The static arrangement of rhythm lends itself well to create tension and direct attention to the tone quality of the phrases. Each instrument is droning over an open string. The resonance of open strings changes the timbre and texture.

The drone of open strings is briefly sustained in the viola and cello parts at measure 65. This helps transition the phrases. Motif 1 is stated, augmented and transposed, in the first violin. That, along with an expression of Fiercely Agitated, further signals a return to section A. The meter is $3 / 4$, which further establishes a beat to extend rhythmic tension. The viola and cello create a dense texture as they share common rhythms while the first and second violins develop freely. Changing from two 
part texture to three-part texture releases tension and quickly establishes tension again as the piece is moving to a quasi-return of section $\mathrm{A}$.

Time is again free of meter at measure 76. The tempo remains the same to smoothly connect the transition. Fragments of the four original motifs are spread into all four instruments, with a strong rhythmic reference to motif 1 occurring in the second violin. All of this combines to an illusion of the return of section A, thus making it the strongest point of the release of tension in section $\mathrm{B}$, and also making it the climax of the section. None of the motifs are directly stated, as motif 1 was at measure 65 . This obscurity hints that it is not a return of section A. The phrase further establishes a reference to section A by allowing performers to freely play and repeat passages of notes that have no rhythm. These passages are all references to motif 2 . The heightened sense of free time strongly alludes to section A, and sets an expectation of its return that creates more tension. By using motif 2 instead of motif 1 , however, the listener is deceived as the strongest motive has not yet been re-established. Therefore, the phrase acts as an interlude to the next phrase.

Meter returns at measure 78 along with the texture established at measure 65 . The themes are further developed and the texture is now spread into four parts. The return of previous material acts as resolution to the climax. Referencing prior tone colors through the use of open-string drones also re-establishes previous material. Tension is built with dynamics and density to measure 82 . At measure 82 , all parts form a brief ostinato to release the final tension of the section at measure 85, ending on light-hearted, short pizzicato notes that act as anticipation of the final return of section A. 
Measure 86 is a final return of section A. It is not stated literally, therefore making it A-prime ( $\left.\mathrm{A}^{\prime}\right)$. The similarities to section $\mathrm{A}$ are that it is in free-time, uses varying tempos in each part, repeats passages, and passes each part to different instruments. The differences are that it begins with all four parts playing at the same time, the expression marking is Whimsical rather than Bitterly and Agitated, the timbre is pizzicato, and the motifs begin fragmented.

Beginning the $\mathrm{A}^{\prime}$ section with fragments is a transition device that smoothly connects it to the previous section. Because of that the form of $\mathrm{A}^{\prime}$ takes a retrograde approach to section $\mathrm{A}$. In section $\mathrm{A}$, each motif is introduced one at a time until they are all playing simultaneously, then it passes and develops the motifs to different instruments. The $\mathrm{A}^{\prime}$ section begins with fragments of all four motifs playing simultaneously, and then introduces, one at a time, a fragment of motif 1 until in measure 95 when motif 1 is re-stated by the viola. Again, one at a time, each instrument joins the viola in the statement of motif 1 until all instruments state the theme in unison. The ending is then just as the beginning, except that all instruments are playing motif 1 , instead of the viola by itself. But, in true retrograde fashion, the viola has already stated the theme on its own and the motif grows to encompass all the instruments.

The final restatement of motif 1 by all the instruments at measure 98 serves as an anti-climax, being just as effective a climax as traditional ones. Traditionally, a climax occurs when a piece reaches a point of much density and dynamic volume after it has restated themes, creating a powerful sense of tension, then resolves into less dense material with lower dynamic volume as a conclusion. The opposite occurs here as the 
piece seemingly releases tension by reaching a point of less density with diminishing dynamic volume and ends with the restatement of the opening theme with no conclusive material. Expectations, therefore, have been denied. That in itself creates much tension and serves as an effective climax that builds tension and resolves it simultaneously.

In conclusion, String Quartet No. 1 unifies itself through many elements. Form and motivic development are closely related as the form is dependent on when and how the development occurs to smoothly connect each part of the piece. Used and re-used throughout the piece are tone colors, such as timbral changes from sul ponticello, pizzicato, and the use of harmonics, as well as using open strings to create rich, warm tones. Motives are stated and restated through the use of transposition. Texture moves through two, three, and four parts effectively and also changes from dense to light to aid in the development of tension and release. Varying tempos in section B mimic the simultaneous and varying tempos of section A. Tempo markings also give liberty to performers to help enliven the piece with a different energy each time the piece is performed. And meter plays an important role in the overall tension/release structure of the piece by establishing and obscuring the beat as well as joining together the varying tempos fluidly. 

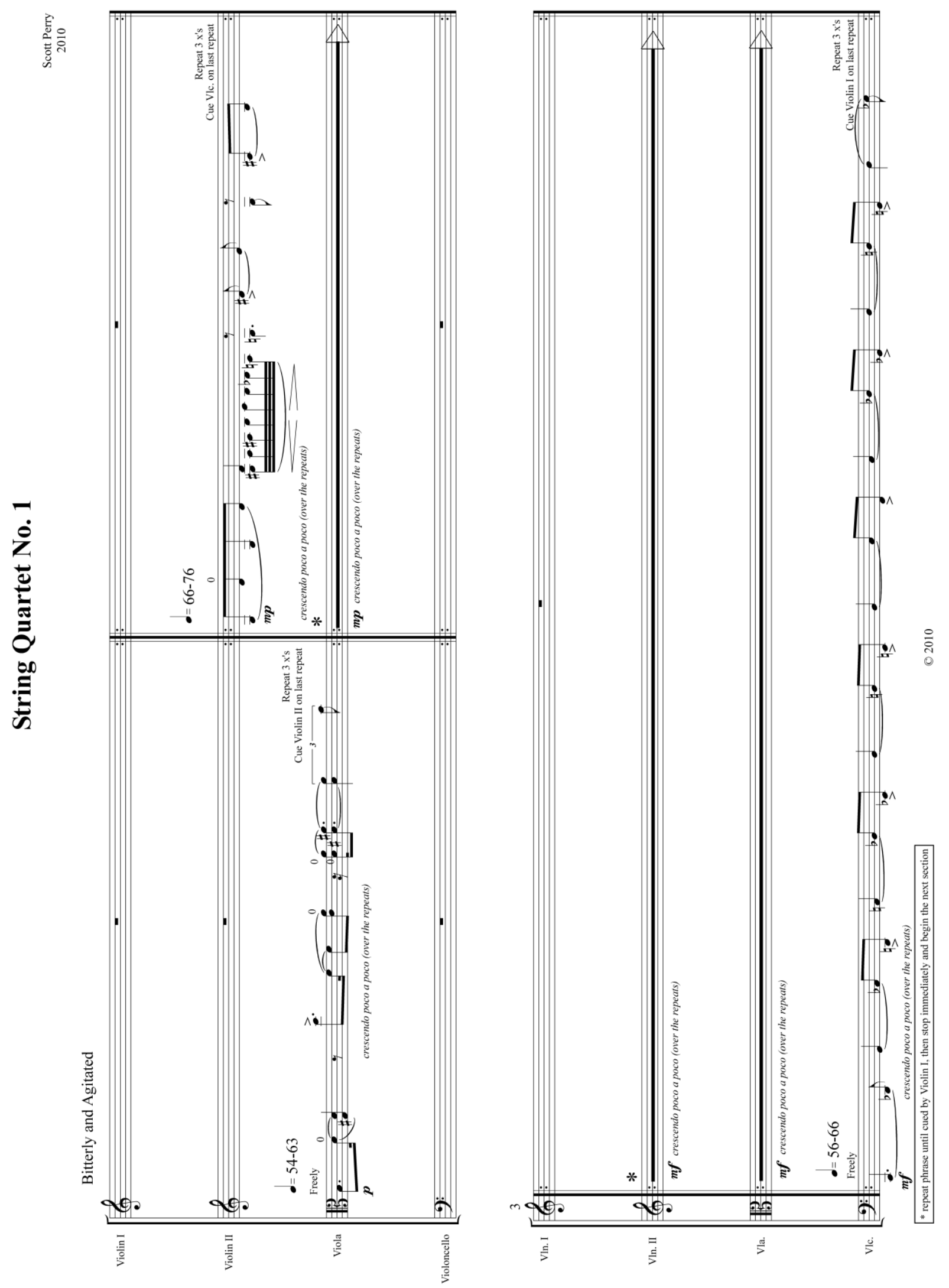

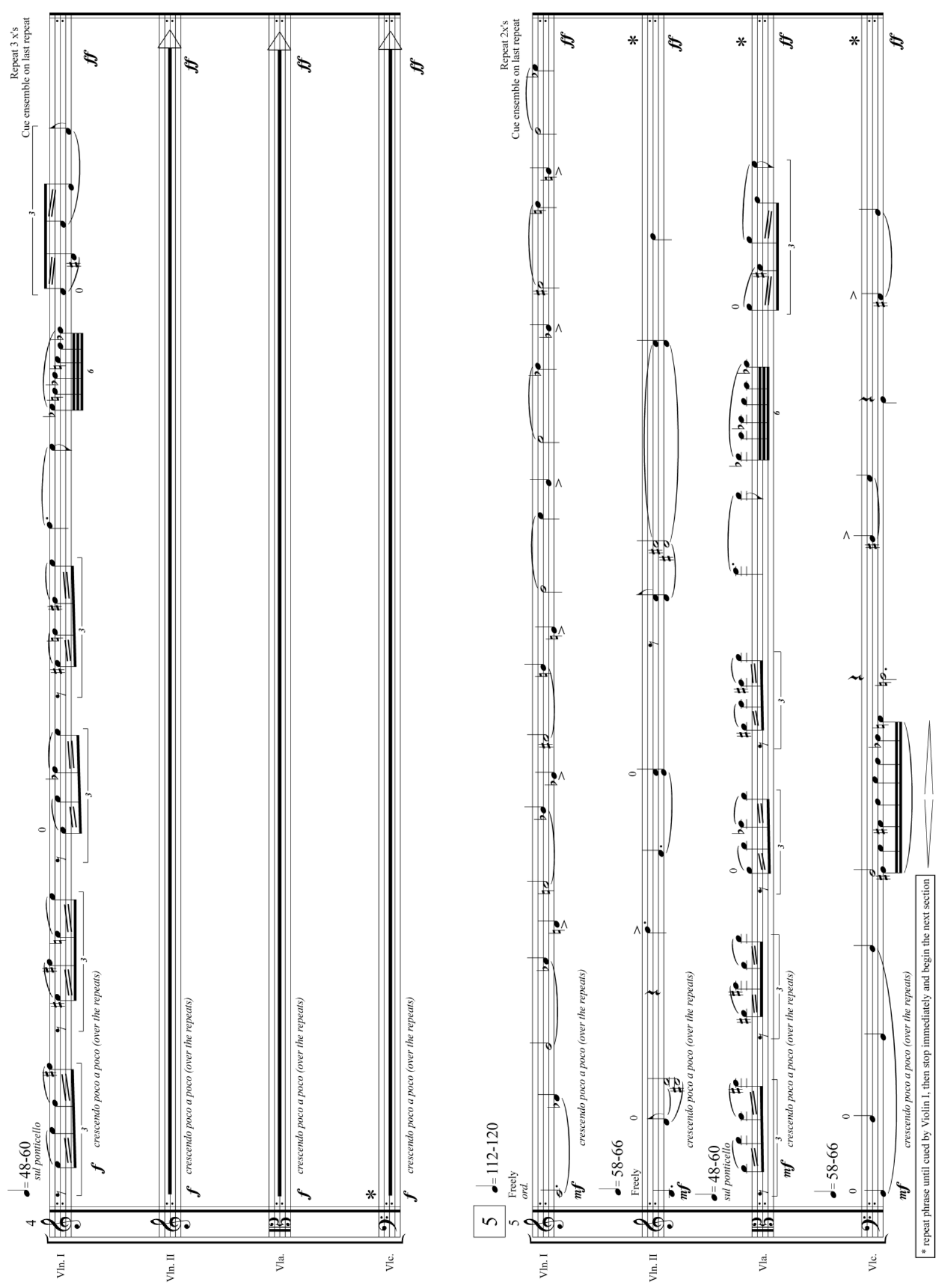

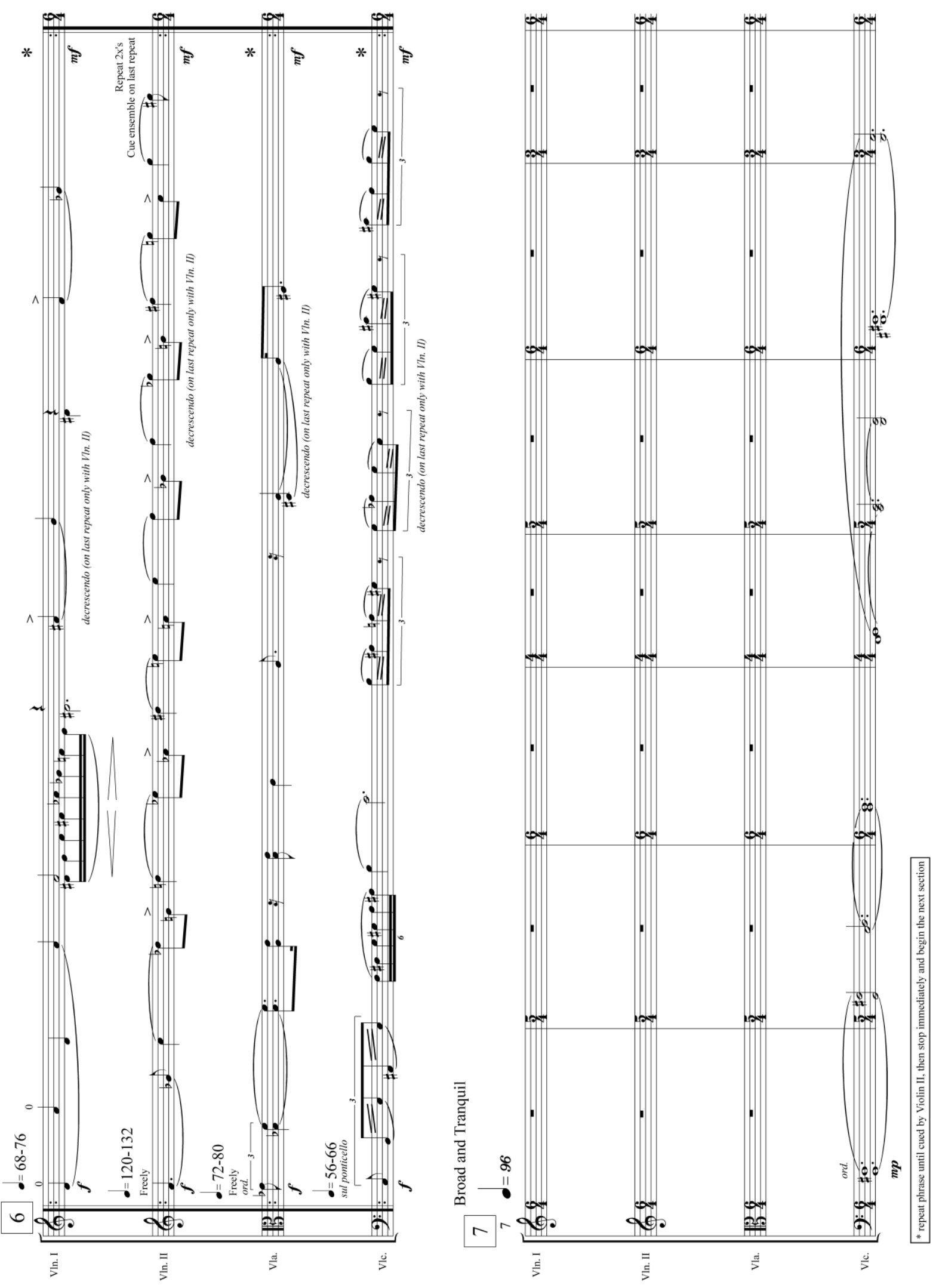

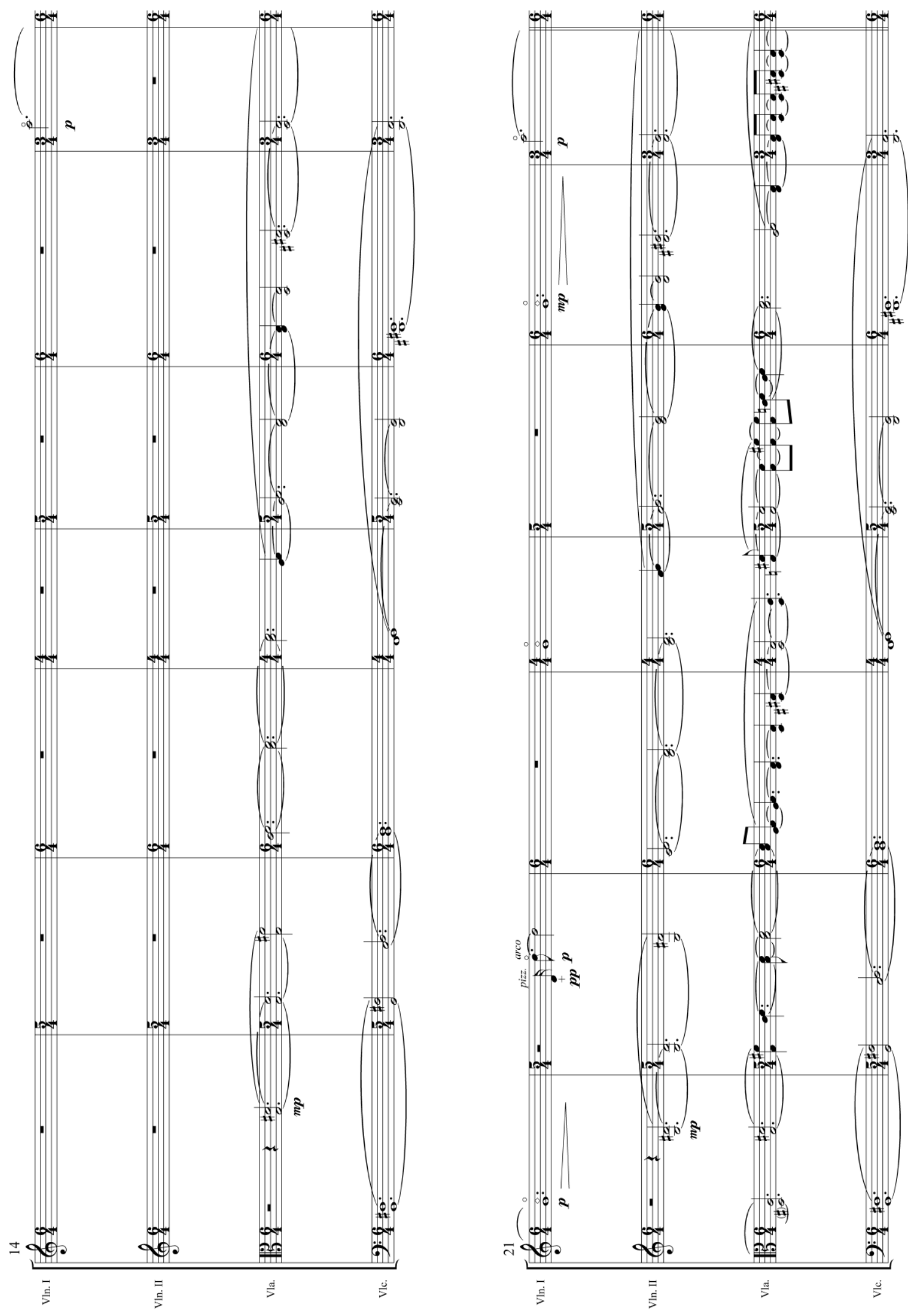

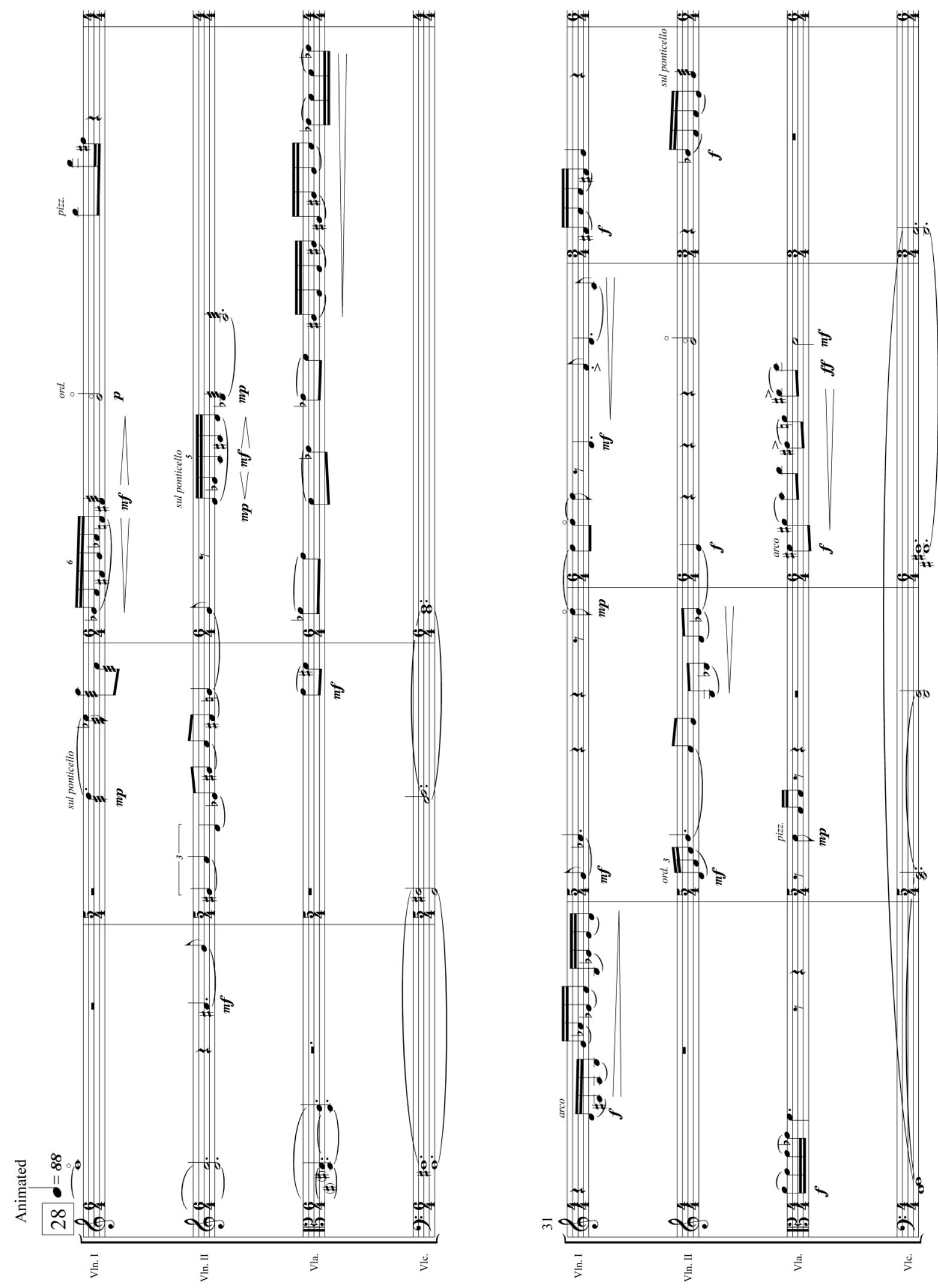

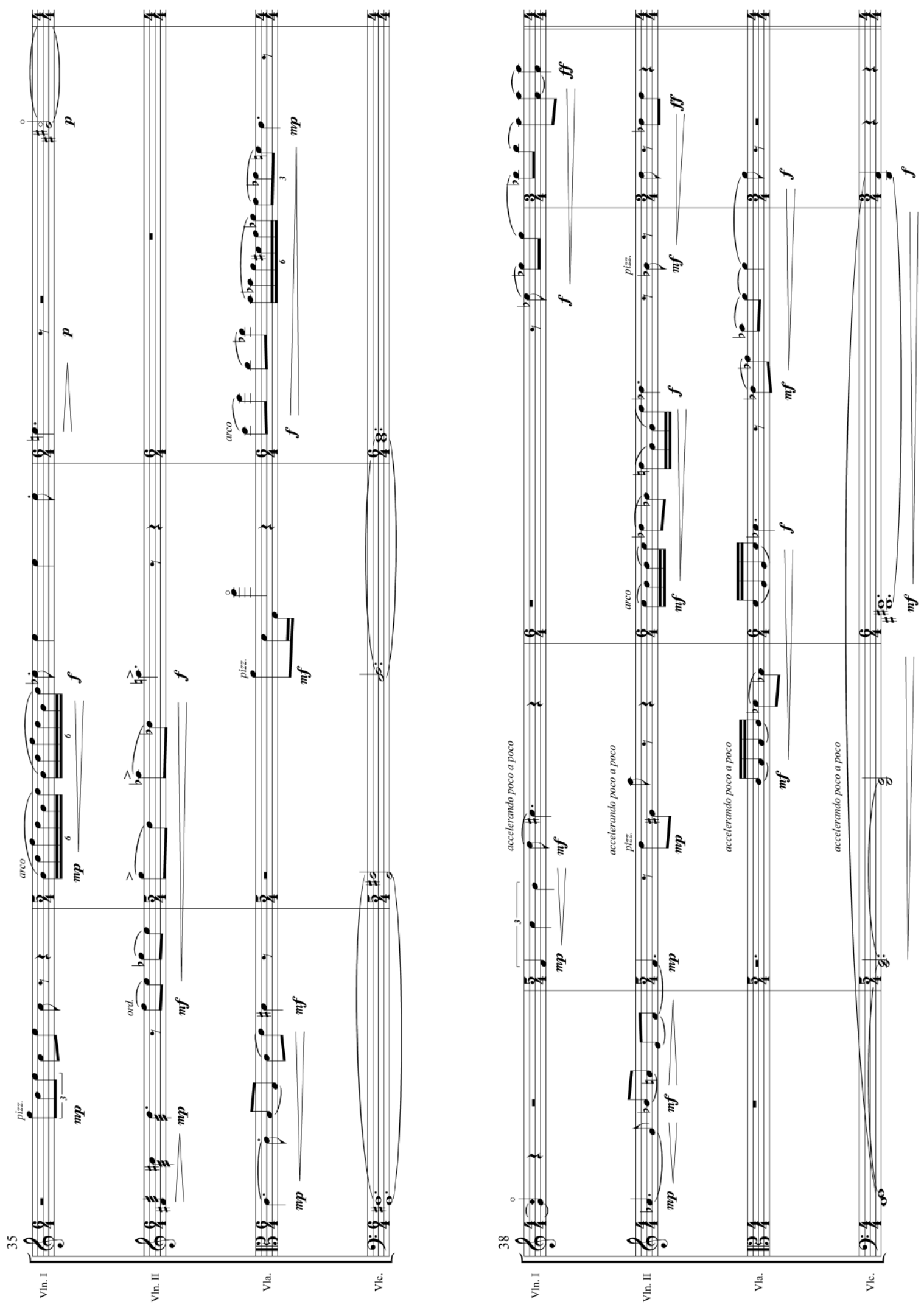

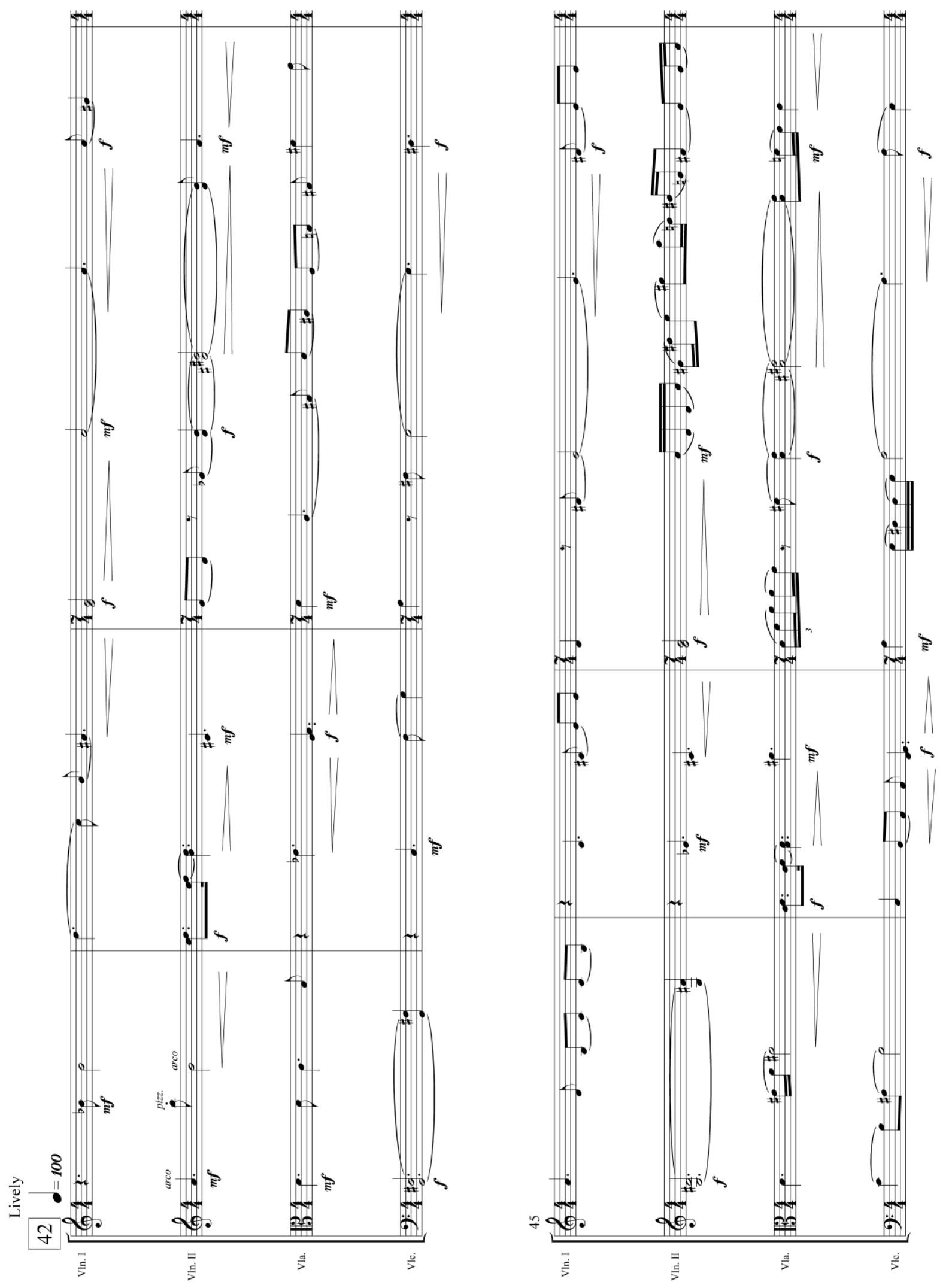

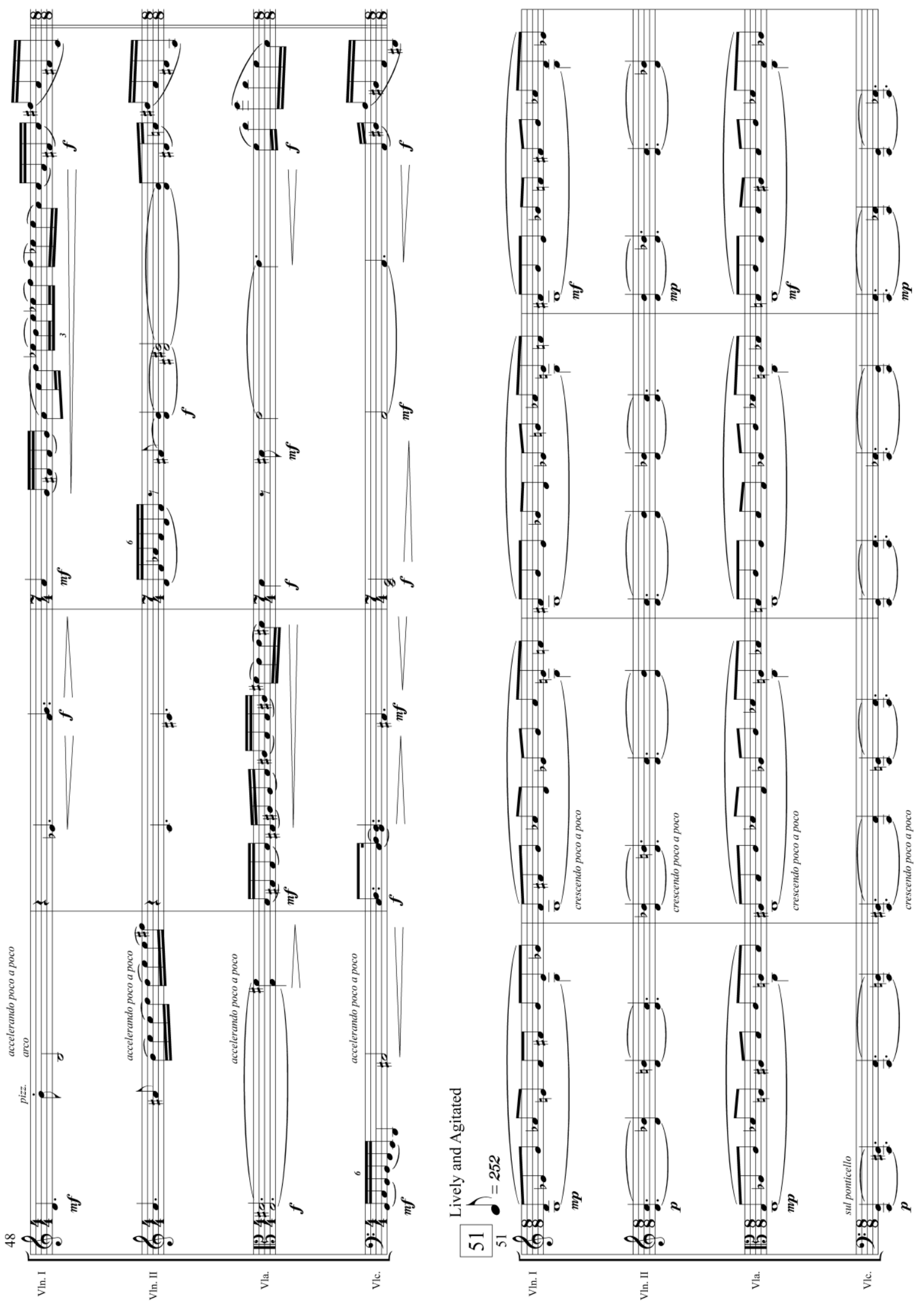

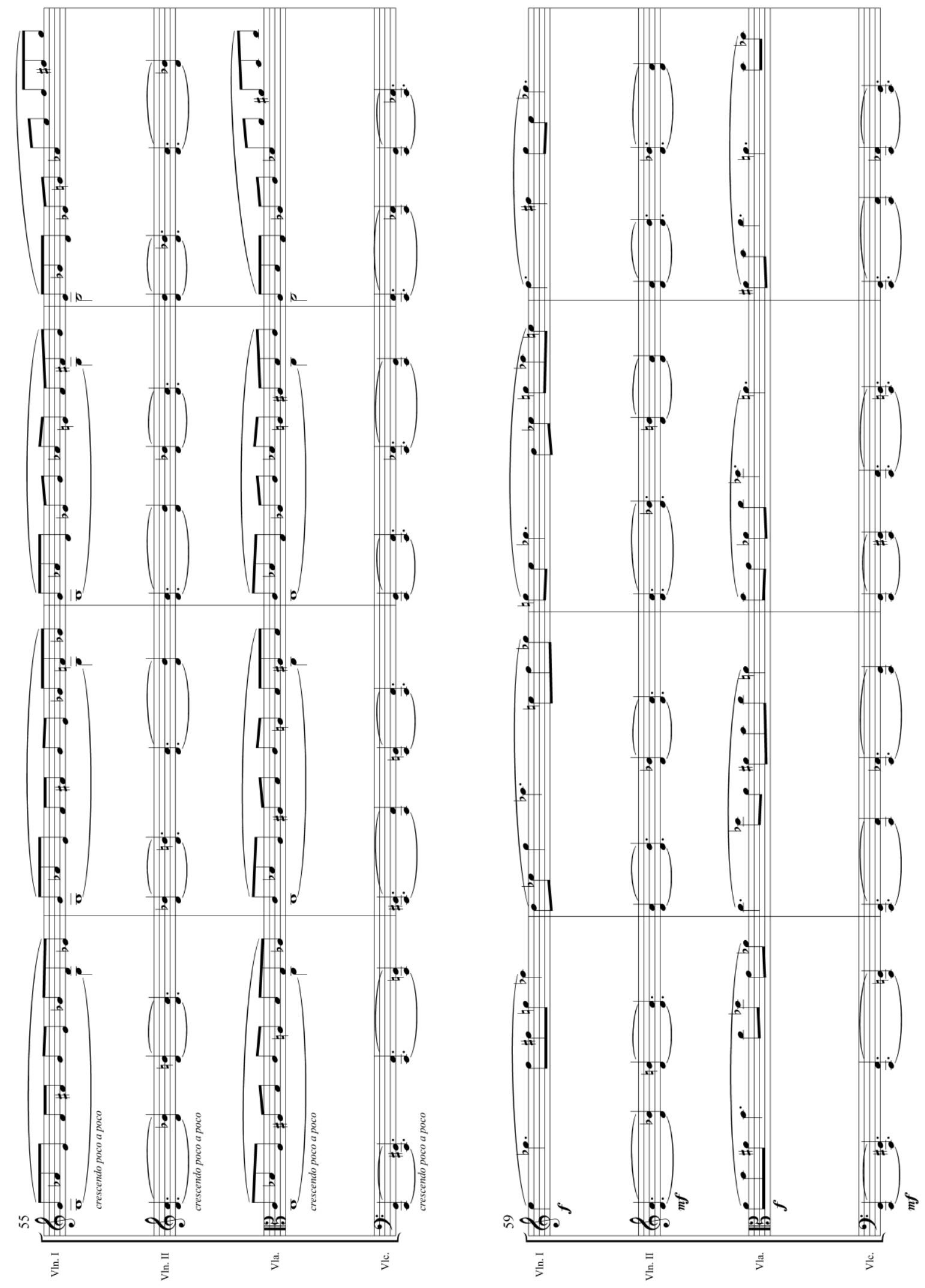

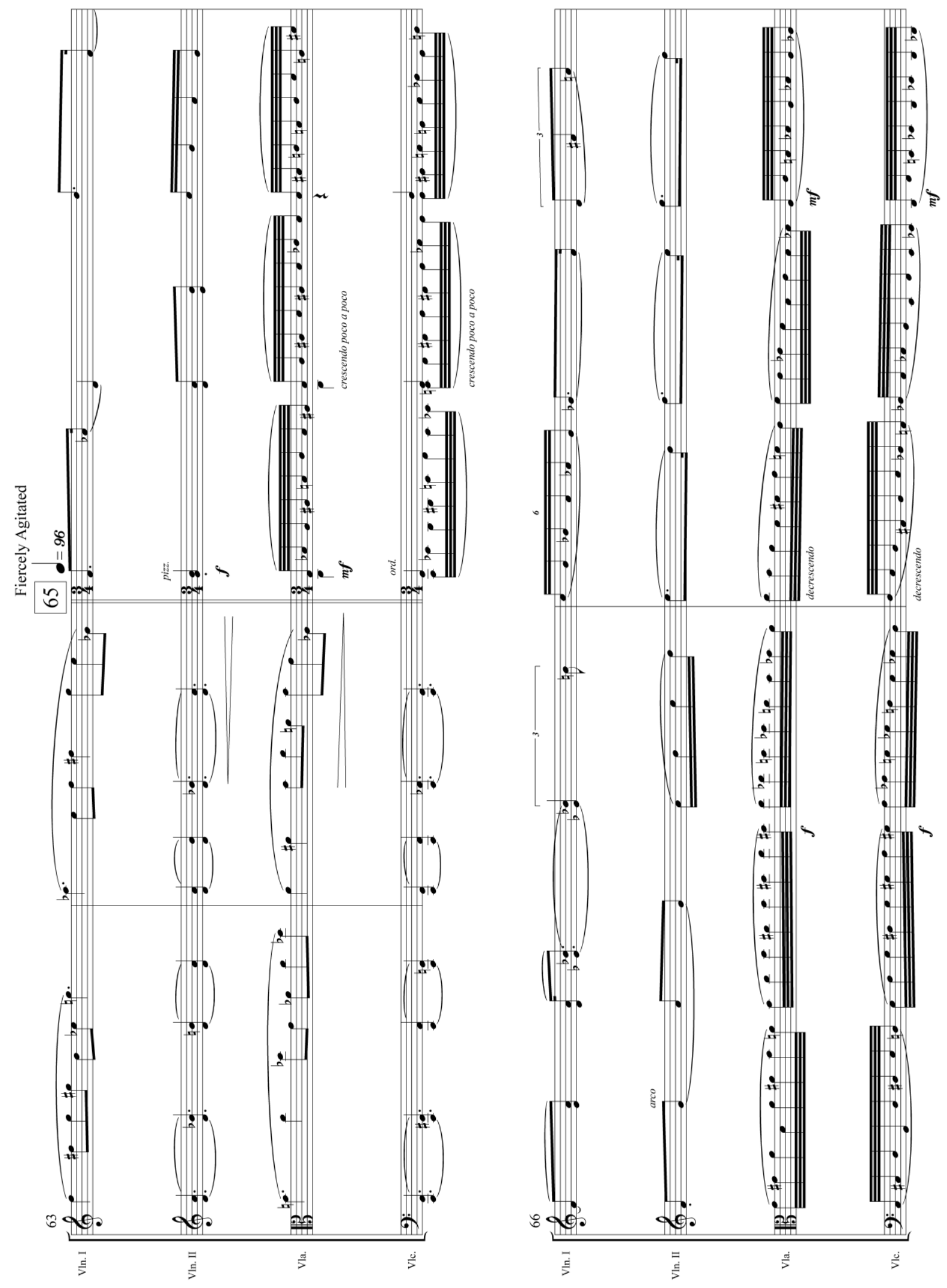

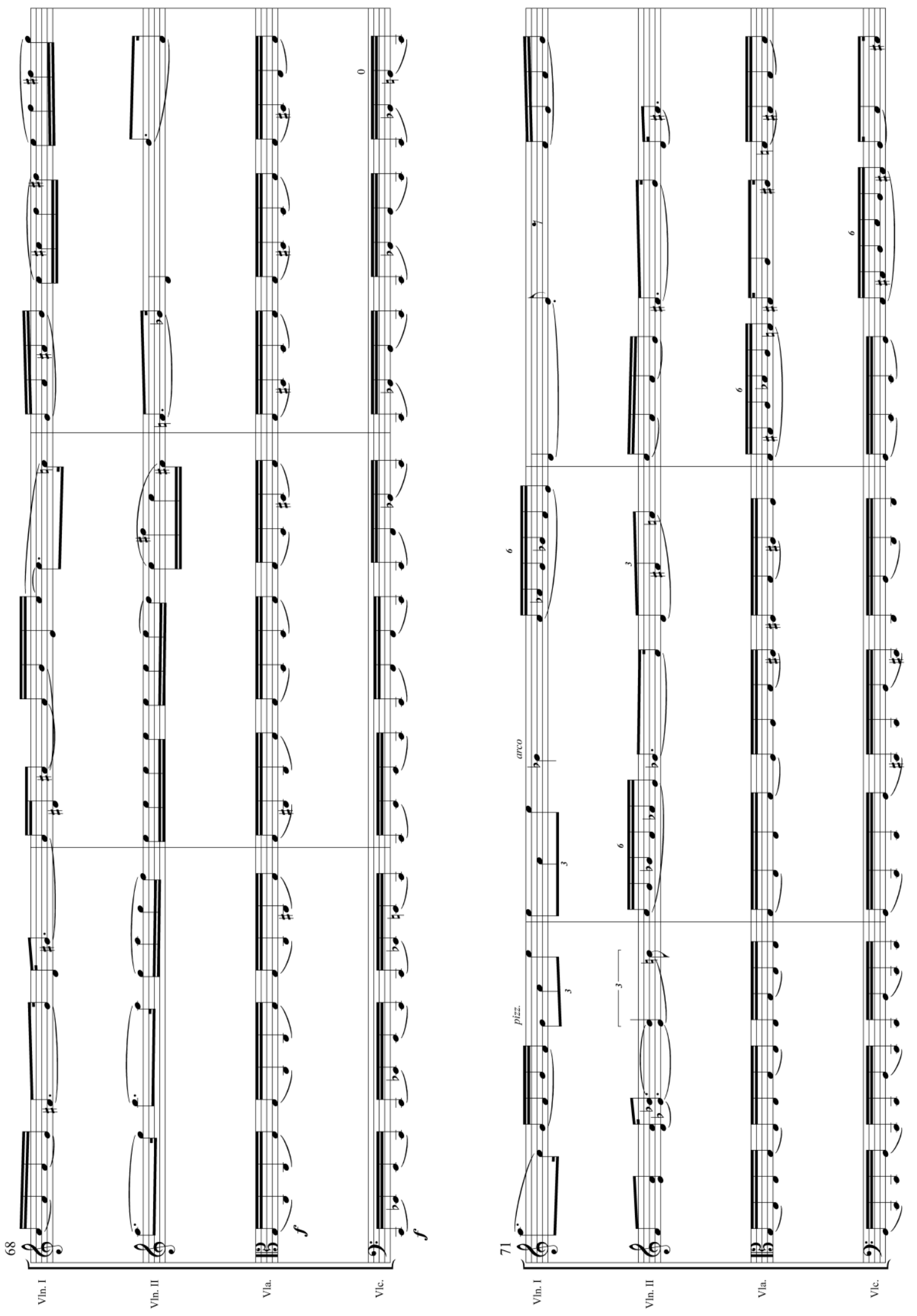

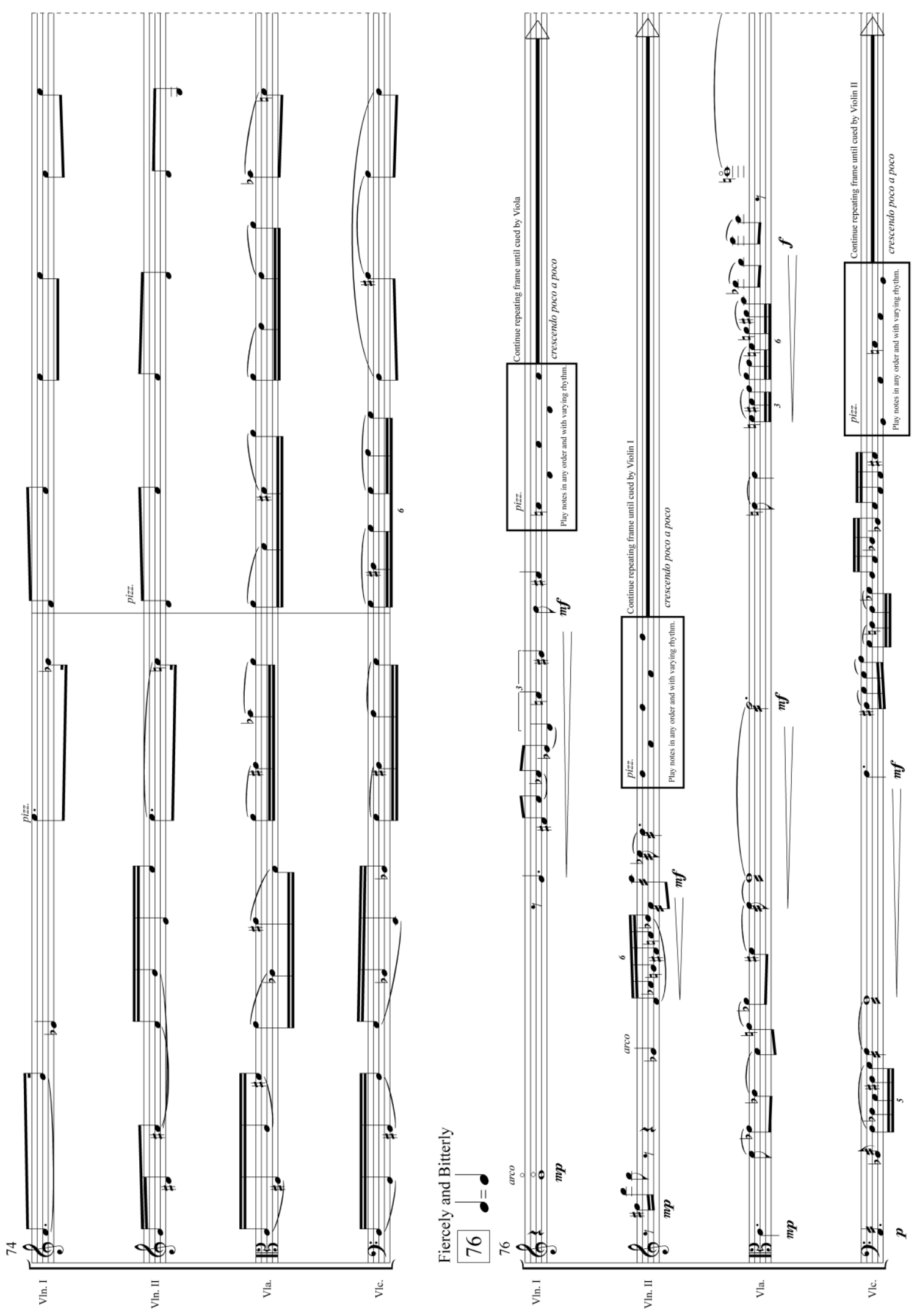

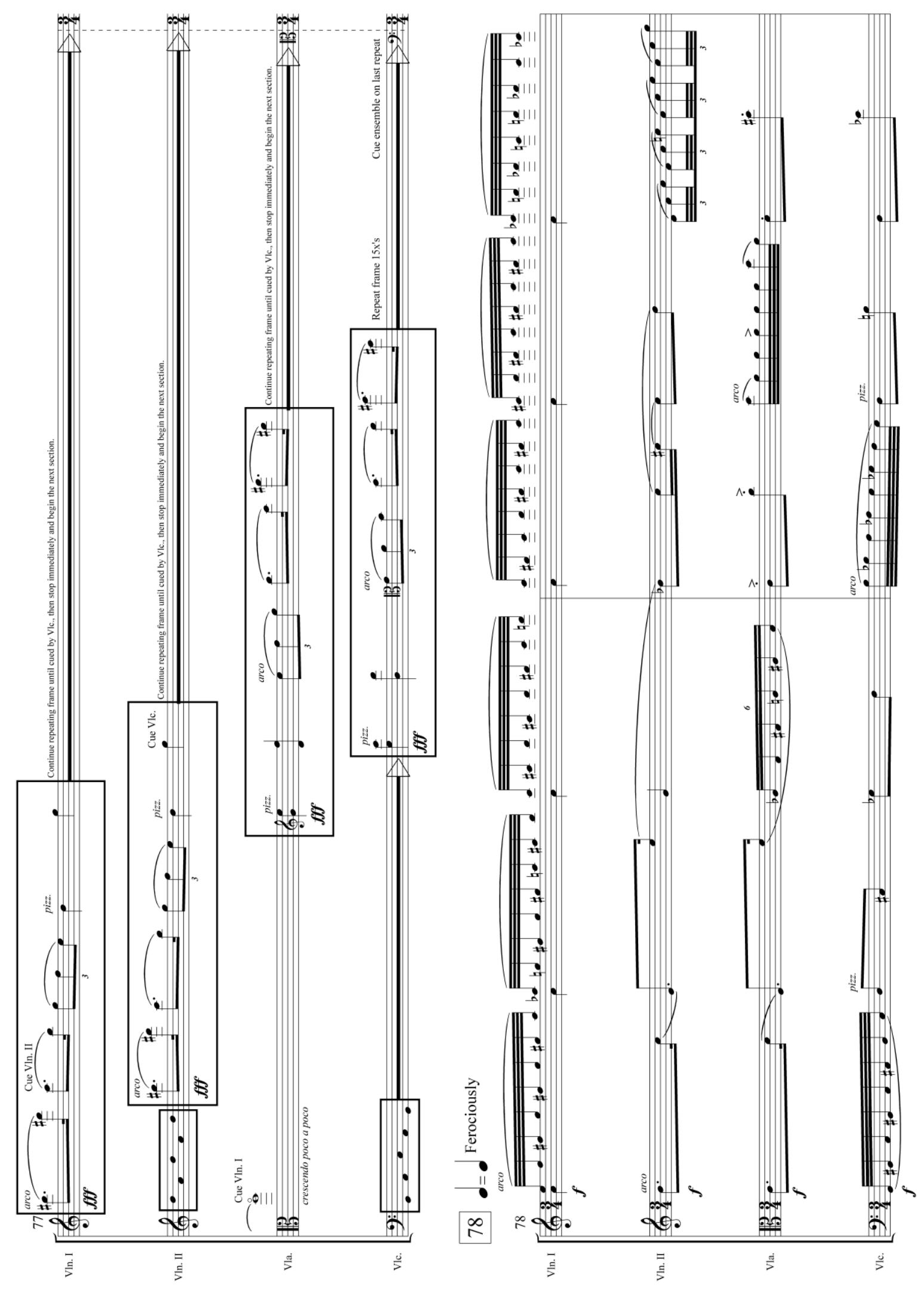

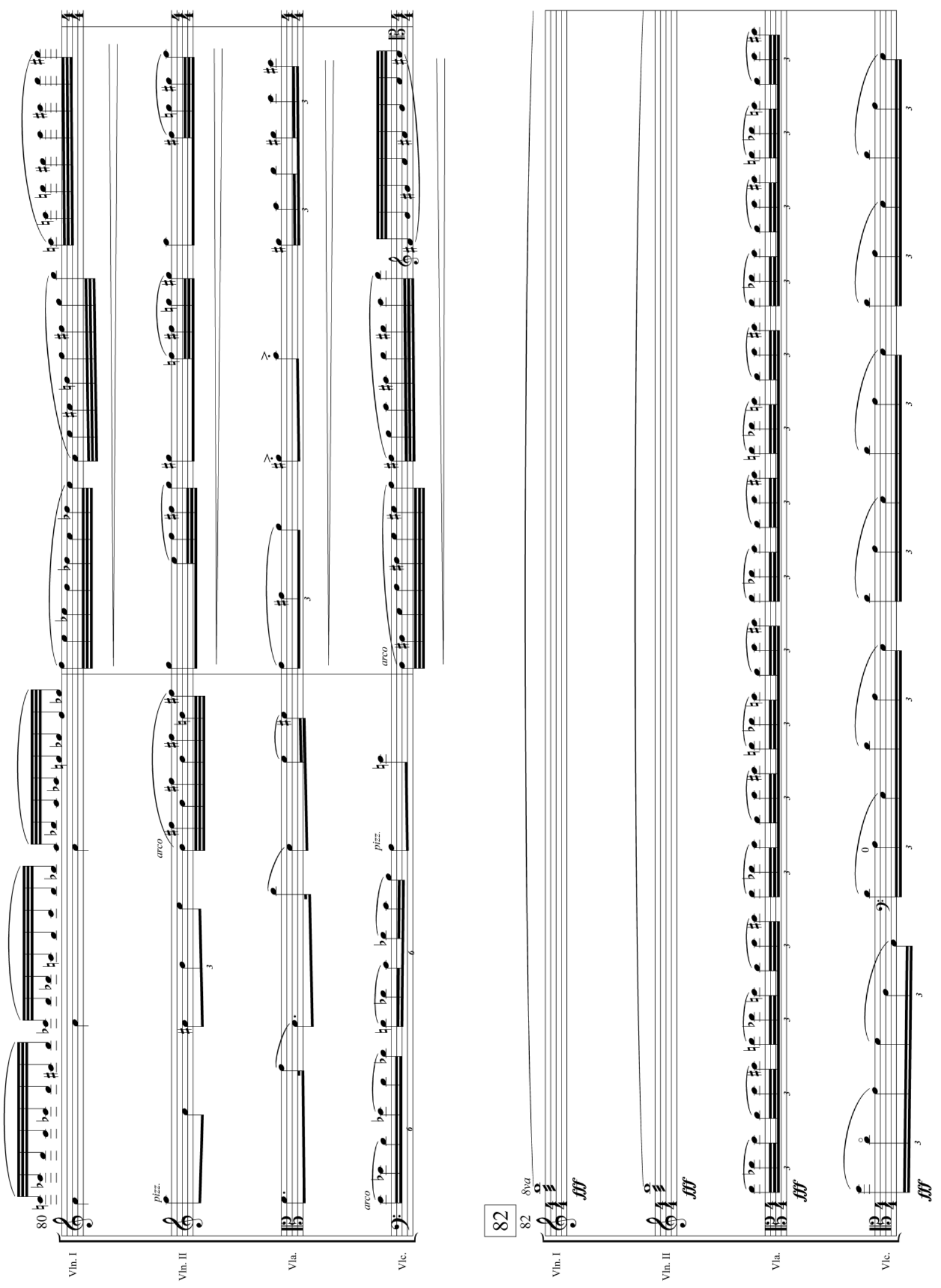

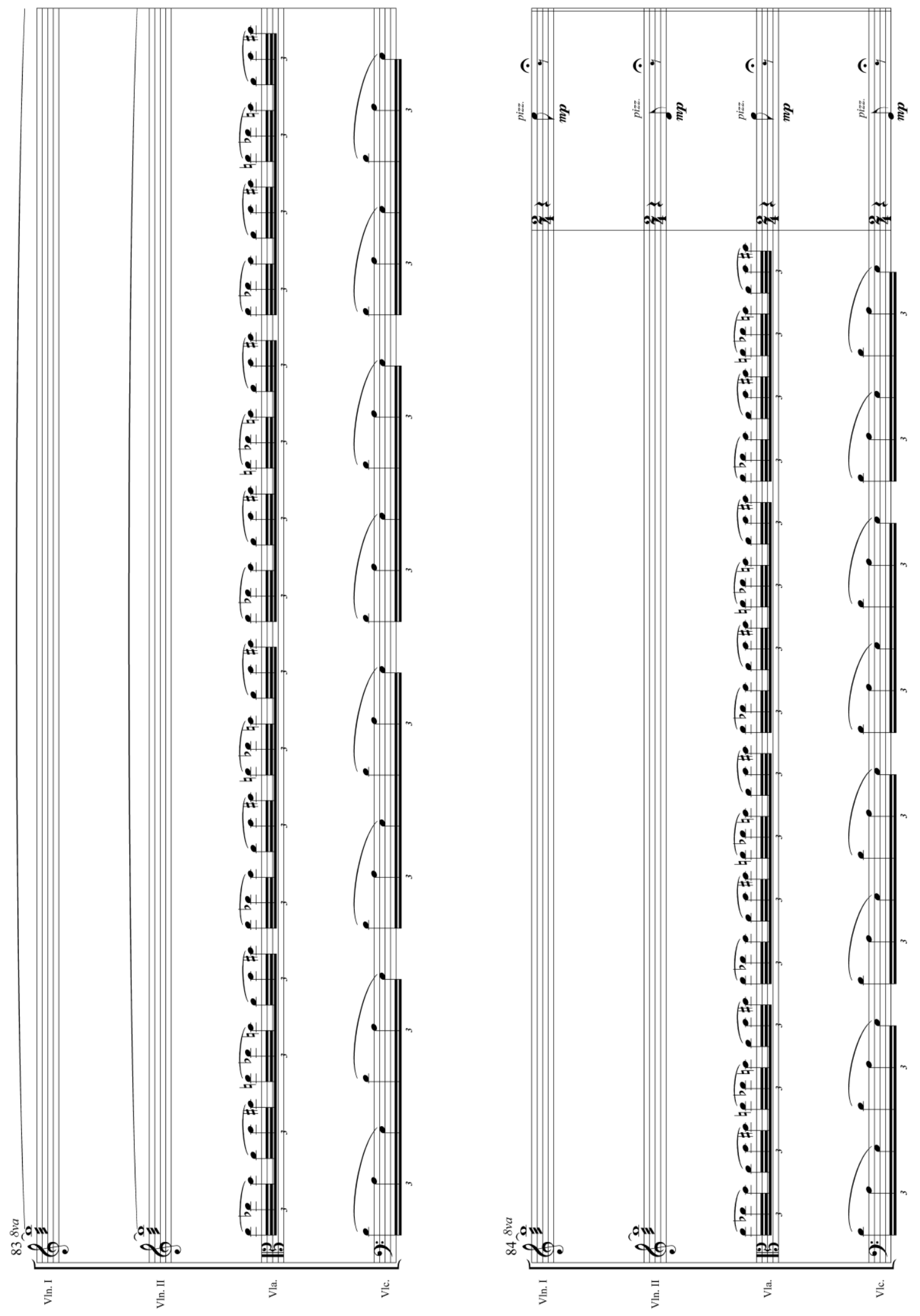

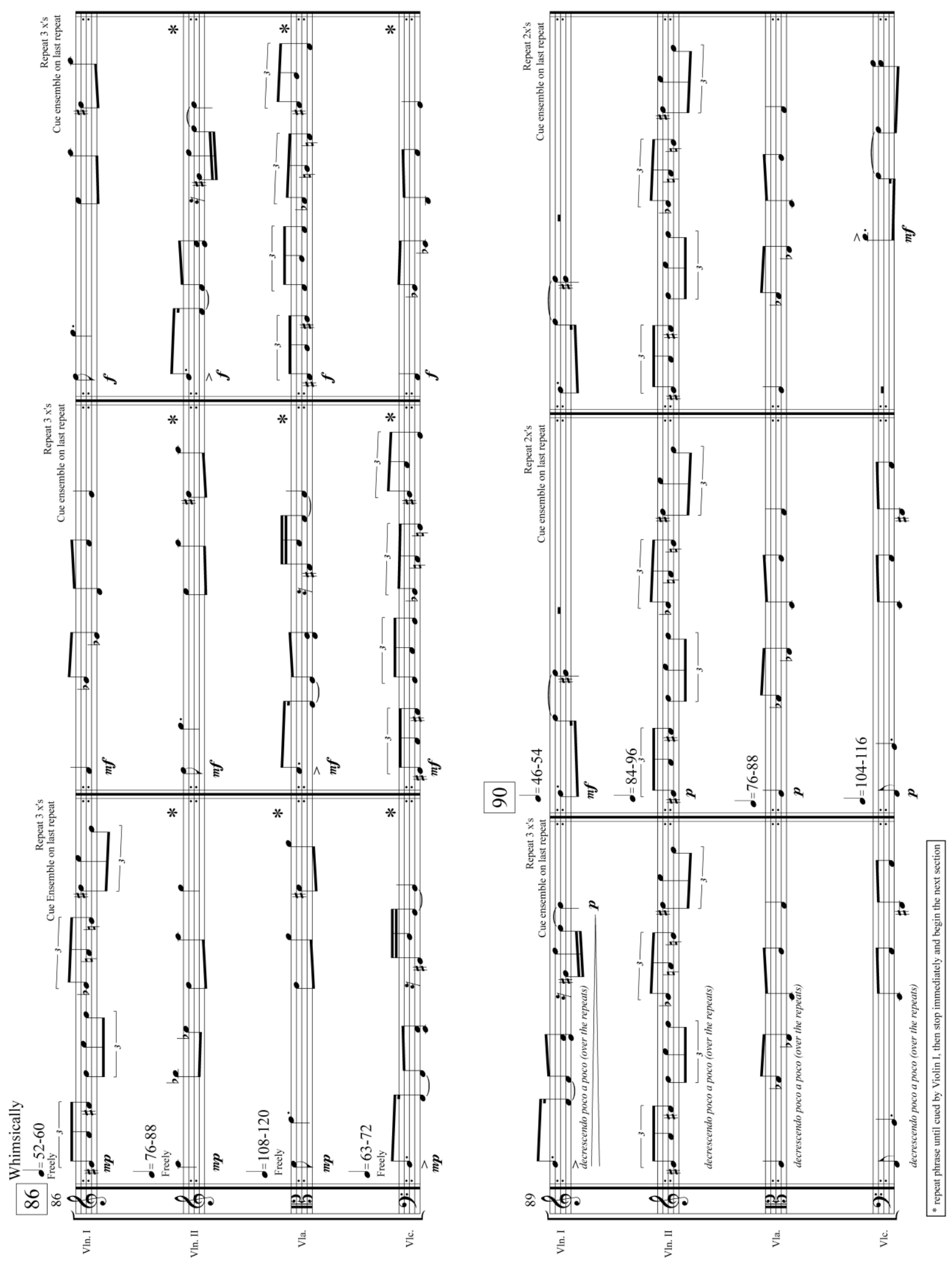

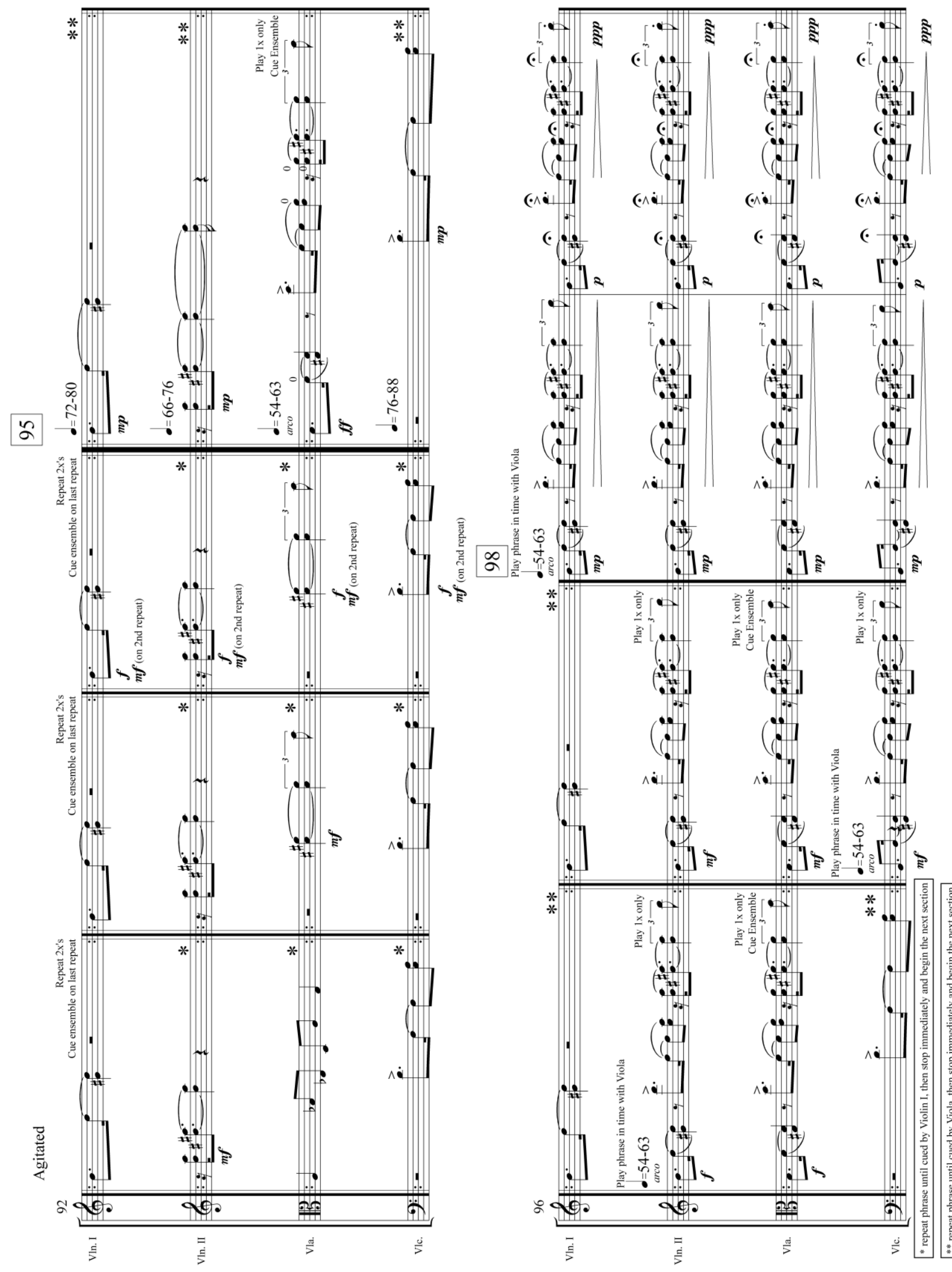

$\infty$
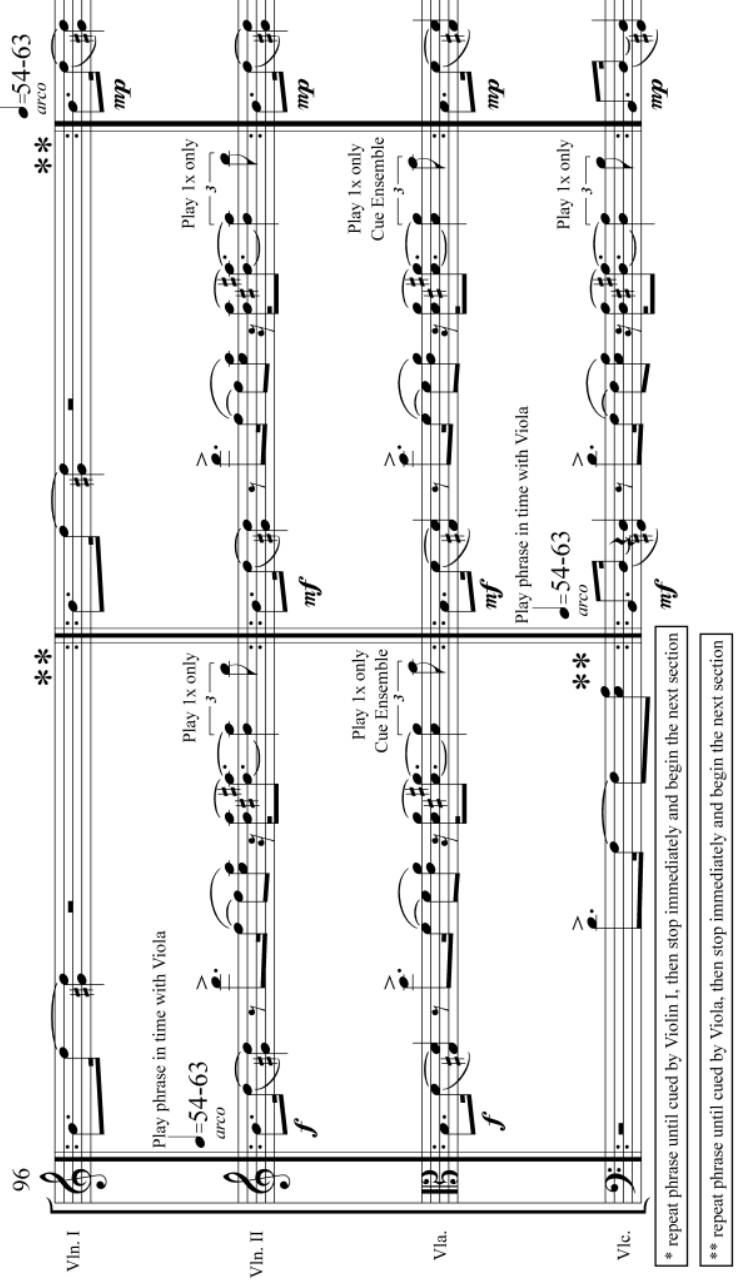